\title{
Constituents of Some Essential Oil Bearing Plants from Vietnam
}

\author{
Le T. M. Chau', Tran D. Thang1*, Le V. Diep', Nguyen T. M. Tu², Isiaka A. Ogunwande ${ }^{3 *}$ \\ ${ }^{1}$ Faculty of Chemistry, Vinh University, Vinh, Vietnam \\ ${ }^{2}$ School of Biotechnology and Food Technology, Hanoi University of Science and Technology, \\ Hanoi, Vietnam \\ ${ }^{3}$ Natural Products Research Unit, Department of Chemistry, Faculty of Science, Lagos State University, \\ Lagos, Nigeria \\ Email: "thangtd@vinhuni.edu.vn, ${ }^{*}$ isiaka.ogunwande@lasu.edu.ng
}

Received 25 December 2013; revised 19 February 2014; accepted 14 March 2014

Copyright (c) 2014 by authors and Scientific Research Publishing Inc.

This work is licensed under the Creative Commons Attribution International License (CC BY).

http://creativecommons.org/licenses/by/4.0/

(c) (1) Open Access

\section{Abstract}

Essential oils obtained from hydrodistillation of three medicinal plants grown in Vietnam were analyzed by gas chromatography (GC) and gas chromatography/mass spectrometry (GC-MS). The monoterpene hydrocarbons, $\alpha$-pinene $(50.2 \%), \beta$-pinene $(23.6 \%)$ and limonene $(5.3 \%)$ were the most abundant constituents of the rhizome oil of Zingiber collinsii Mood \& Theilade (Zingiberaceae). The main compounds of the stem oil of Croton kongensis Gagnep., (Euphorbiaceae) were benzyl benzoate $(12.7 \%), \beta$-selinene $(9.8 \%)$, bulnesol $(8.0 \%)$ and $5,6,7,8$-tetrahydroquinoxaline (7.4\%). The leaf oil of Goniothalamus albiflous Ban., consisted mainly of $\alpha$-pinene (26.2\%), caryophyllene oxide (10.6\%) and 1,8-cineole (9.7\%). The composition of the oils of Zingiber collinsii and Croton kongensis was being reported for the first time.

\section{Keywords}

Zingiber collinsii; Croton kongensis; Goniothalamus albiflorus; Essential Oil; Terpenes

\section{Introduction}

In this paper, we report on the volatile constituents identified from the three medicinal plants, as part of our continued interest on the chemical analysis of the flora of Vietnam [1] [2]. Zingiber collinsii Mood \& Theilade (Family Zingiberacea), a deciduous species, was recently collected in Vietnam and introduced by Mark Collins [3]. Naturally dormant in winter, leaves have silver streaks on green above and maroon beneath. Cones are dull

${ }^{*}$ Corresponding authors. 
orange and form at the base of the plant. It is the most beautiful ginger in cultivation. The foliage is spectacular with silver bands on the leaves and basal flowers in clusters of orange to red that look like brightly colored hot pokers [4]. Literature information is scanty on its volatile and non-volatile constituents as well as the biological potential of this plant.

Croton kongensis Gagnep., (family Euphorbiaceae), is known in Vietnam as Cù đèn cửu long. The leaves are used for medicinal purposes. It is frequently used in folk medicine for dysmenorrhoea. The leaves are used in Indo-China for various stomach disorders including ulcers, and a decoction is externally applied for furuncles and impetigo [5]. Crude extract of the plant was previously reported to have exhibited antimalarial and antimycobacterial activities [5]. Several metabolites including antimycobacterial and antimalarial diterpenes [6]-[9] and phenolic compounds [9] have been characterized from this plant. The volatile constituent has not been any subject of literature discussion.

Goniothalamus albiflorus Ban., is a species of plant in the Annonaceae family. This plant is endemic to Vietnam [10]. A previous analysis of the volatile constituents identified higher amounts of benzoic acid (18.4\%), $\beta$-caryophyllene (12.4\%) and $\alpha$-pinene (10.3\%) leaf oil, while limonene (21.2\%), $\beta$-caryophyllene (12.8\%) and $\alpha$-phellandrene (9.3\%) were present in stem oil [11].

\section{Materials and Methods}

\subsection{Plants Collection}

Rhizomes of Z. collinsii and the stem of C. kongensis were collected from Pu Mat National Park, Nghe An Province in July 2012 and September 2011 respectively. The leaves of G. albiflorus were collected from Bạch Mã National Park, Thừa Thiên-Huế Province, Vietnam, in August 2011. Voucher specimens were coded DND 278, HDT 288 and DND 807 respectively. All specimens were deposited at the Botany Museum Vinh University, Vietnam.

\subsection{Isolation of Essential Oils}

$0.5 \mathrm{Kg}$ of air-dried of each plant sample was shredded and their oils were obtained by hydrodistillation for $3 \mathrm{~h}$ at normal pressure, according to the Vietnamese Pharmacopoeia [12].

\subsection{Gas Chromatography (GC) Analysis of the Oils}

Gas chromatography (GC) analysis was performed on Agilent Technologies HP 6890 Plus Gas chromatograph equipped with an FID and fitted with HP-5MS column $(30 \mathrm{~m} \times 0.25 \mathrm{~mm}$, film thickness $0.25 \mu \mathrm{m}$, Agilent Technology). The analytical conditions were: carrier gas $\mathrm{H}_{2}(2 \mathrm{~mL} / \mathrm{min})$, injector temperature (PTV) $250^{\circ} \mathrm{C}$, detector temperature $260^{\circ} \mathrm{C}$, column temperature programmed $60^{\circ} \mathrm{C}$ (2 min hold) to $220^{\circ} \mathrm{C}$ (10 min hold) at 4 ${ }^{\circ} \mathrm{C} / \mathrm{min}$. Samples were injected by splitting and the split ratio was 10:1. The volume injected was $1.0 \mu \mathrm{L}$. Inlet pressure was $6.1 \mathrm{kPa}$. The relative amounts of individual components were calculated based on the GC peak area (FID response) without using correction factors.

\subsection{Gas Chromatography-Mass Spectrometry (GC-MS) Analysis of the Oils}

An Agilent Technologies HP 6890N Plus Chromatograph fitted with a fused silica capillary column HP-5 MS column (30 m $\times 0.25 \mathrm{~mm}$, film thickness $0.25 \mu \mathrm{m})$ and interface with a mass spectrometer HP 5973 MSD was used for the GC/MS analysis, under the same condition for GC analysis. The conditions were the same as described above with He (1 mL/min) as carrier gas. The MS conditions were as follows: ionization voltage $70 \mathrm{eV}$; emission current $40 \mathrm{~mA}$; acquisitions scan mass range of 35 - $350 \mathrm{amu}$ at a sampling rate of $1.0 \mathrm{scan} / \mathrm{s}$. The MS fragmentation patterns was checked with those of other essential oils of known composition patterns with Wiley (Wiley $9^{\text {th }}$ Version), NIST 08 Libraries (on ChemStation HP), with those in the literature and also with standard substances.

\subsection{Identification of Constituents}

The identification of constituents was performed on the basis of retention indices (RI) determined with reference to the homologous series of $n$-alkanes, under identical experimental conditions, co-injection with standards 
(Sigma-Aldrich, St. Louis, MO, USA) or known essential oil constituents, MS library search (NIST 08 and Wiley $9^{\text {th }}$ Version), and by comparing with MS literature data [13] [14].

\section{Results and Discussion}

The yields obtained from the hydrodistillation procedures were $0.20 \%$ (v/w; Z. collinsii; light yellow), $0.12 \%$ (v/w; C. kongensii (colourless) and $0.25 \%$ (v/w; G. albiflorus, light yellow). All calculations were done on a dry weight basis. Table 1 displays the identities of compounds identified from the studied oil samples. 35 compounds representing $96.9 \%$ of the total contents were identified from the oil of $Z$. collinsii. Monoterpene hydrocarbons (89.9\%) were the exclusive class of compound identified in Z. collinsii. The main compounds in this class were $\alpha$-pinene (50.2\%), $\beta$-pinene (23.6\%) and limonene (5.3\%). The oxygenated monoterpenes and the sesquiterpene compounds, though present in the oil were identified in lesser quantities. This report was the first attempt on the analysis of the volatile constituents of this plant. Recently, the major constituents of rhizome oil of Vietnamese Zingiber rubens were identified as (Z)-citral (30.1\%), camphene (9.7\%), $\beta$-phellandrene (7.5\%) and 1,8-cineole (7.0\%) and zingiberene (5.3\%) while (Z)-citral (26.1\%), camphene (16.3\%), sabinene (14.6\%), zingiberene (7.2\%) and lavandulyl acetate (6.7\%) were the principal compounds of Zingiber zerumbet [1]. It was noted that all the main constituents of $Z$. rubens and $Z$. erumbet except camphene were conspicuously absent in Z. collinsii.

Table 1. Compounds identified from the studied samples.

\begin{tabular}{|c|c|c|c|c|c|}
\hline \multirow{2}{*}{ Compounds } & \multirow{2}{*}{ RI } & \multirow{2}{*}{$\mathbf{R I}$} & \multicolumn{3}{|c|}{ Percent composition (\%) } \\
\hline & & & Z.c & C.k & G.a \\
\hline$\alpha$-Pinene & 939 & 932 & 50.2 & 5.4 & 26.2 \\
\hline Camphene & 953 & 946 & 2.3 & 2.3 & 1.7 \\
\hline Verbenene & 968 & 961 & 0.2 & - & 1.0 \\
\hline$\beta$-Pinene & 980 & 974 & 23.6 & 2.1 & 2.2 \\
\hline$\beta$-Myrcene & 990 & 988 & 2.9 & 3.5 & - \\
\hline$\alpha$-Phellandrene & 1006 & 1002 & 1.3 & - & - \\
\hline$\alpha$-Terpinene & 1017 & 1014 & 0.3 & - & - \\
\hline p-Cymene & 1024 & 1020 & - & - & 0.3 \\
\hline Limonene & 1032 & 1024 & 5.3 & 0.7 & 0.4 \\
\hline 1,8-Cineole & 1034 & 1026 & - & - & 9.7 \\
\hline (Z)- $\beta$-Ocimene & 1043 & 1032 & 0.5 & - & 0.1 \\
\hline (E)- $\beta$-Ocimene & 1052 & 1044 & 0.2 & - & 2.2 \\
\hline$\gamma$-Terpinene & 1061 & 0154 & 1.0 & - & - \\
\hline$\alpha$-Terpinolene & 1090 & 1086 & 0.5 & - & - \\
\hline Linalool & 1100 & 1095 & 0.2 & 0.4 & - \\
\hline 1,3,8-p-Menthatriene & 1110 & 1108 & - & - & 0.1 \\
\hline$\alpha$-Campholenal & 1126 & 1122 & - & - & 0.4 \\
\hline allo-ocimene & 1128 & 1128 & 0.1 & - & - \\
\hline trans-Verbenol & 1145 & 1140 & - & - & 1.8 \\
\hline Isoborneol & 1162 & 1155 & - & - & 0.6 \\
\hline Pinocarvone & 1165 & 1160 & - & - & 1.1 \\
\hline Borneol & 1167 & 1165 & - & 0.6 & - \\
\hline Terpinen-4-ol & 1177 & 1174 & 0.1 & - & - \\
\hline$\alpha$-Terpineol & 1189 & 1187 & - & - & 0.7 \\
\hline Myrtenal & 1190 & 1195 & - & - & 1.3 \\
\hline Mesitol & 1204 & 1202 & - & 1.1 & - \\
\hline Verbenone & 1205 & 1204 & - & - & 0.5 \\
\hline trans-Carveol & 1217 & 1215 & - & - & 0.2 \\
\hline 5,6,7,8-Tetrahydroquinoxaline & 1226 & 1226 & - & 7.4 & - \\
\hline Fenchyl acetate & 1228 & 1228 & 0.6 & - & - \\
\hline Z-Citral (=Neral) & 1238 & 1235 & - & - & 2.3 \\
\hline Carvone & 1243 & 1239 & - & - & 0.1 \\
\hline Bornyl acetate & 1289 & 1287 & 0.4 & 1.2 & 0.5 \\
\hline
\end{tabular}




\section{Continued}

\begin{tabular}{|c|c|c|c|c|c|}
\hline trans-Pinocarvyl acetate & 1297 & 1298 & 0.2 & - & 1.7 \\
\hline Bicycloelemene & 1337 & 1338 & 0.4 & - & - \\
\hline$\delta$-Elemene & 1340 & 1335 & - & 2.1 & - \\
\hline$\alpha$-Cubebene & 1351 & 1345 & - & - & 2.5 \\
\hline$\alpha$-Ylangene & 1375 & 1373 & - & - & 4.0 \\
\hline$\alpha$-Copaene & 1377 & 1374 & 0.1 & - & 0.6 \\
\hline$\beta$-Elemene & 1391 & 1389 & 0.1 & 1.9 & - \\
\hline$\beta$-Caryophyllene & 1419 & 1417 & - & 3.5 & 0.1 \\
\hline Aromadendrene & 1441 & 1439 & 0.1 & - & 2.7 \\
\hline$\alpha$-Humulene & 1454 & 1452 & - & 2.0 & - \\
\hline Dehydroaromadendrene & 1463 & 1460 & - & - & 3.3 \\
\hline$\gamma$-Gurjunene & 1479 & 1475 & 0.1 & - & - \\
\hline$\gamma$-Curcumene & 1480 & 1481 & - & 1.0 & - \\
\hline Germacrene D & 1484 & 1484 & - & 2.8 & - \\
\hline$\alpha$-Amorphene & 1485 & 1483 & - & - & 0.1 \\
\hline$\beta$-Selinene & 1484 & 1489 & 0.1 & 9.8 & - \\
\hline cis-Cadina-1,4-diene & 1496 & 1495 & - & - & 2.3 \\
\hline$\alpha$-Selinene & 1498 & 1498 & 0.8 & - & - \\
\hline$\alpha$-Chamigrene & 1505 & 1503 & - & 2.0 & - \\
\hline$(E, E)$ - $\alpha$-Farnesene & 1513 & 1505 & 0.2 & - & - \\
\hline cis-Calamenene & 1514 & 1513 & - & - & 2.4 \\
\hline$\gamma$-Cadinene & 1514 & 1513 & - & 1.8 & 0.6 \\
\hline 7-epi- $\alpha$-Selinene & 1515 & 1520 & 0.1 & 1.2 & - \\
\hline$\alpha$-Calacorene & 1544 & 1544 & - & - & 4.7 \\
\hline Cadina-4,9-diene & 1546 & 1546 & - & - & 1.4 \\
\hline Elemol & 1550 & 1548 & - & 0.4 & - \\
\hline (E)-Nerolidol & 1563 & 1561 & 0.1 & 1.0 & - \\
\hline Palustrol & 1567 & 1567 & - & - & 0.3 \\
\hline Spathulenol & 1578 & 1577 & 0.2 & 2.3 & - \\
\hline Caryophyllene oxide & 1583 & 1582 & - & 2.2 & 10.6 \\
\hline$\alpha$-Guaiol & 1601 & 1600 & - & 1.2 & - \\
\hline Ledol & 1604 & 1602 & - & - & 3.2 \\
\hline epi-Cedrol & 1617 & 1618 & - & 1.6 & - \\
\hline Alloaromadendrene epoxide & 1641 & 1639 & - & - & 0.4 \\
\hline$\alpha$-Cadinol & 1652 & 1652 & 0.1 & 1.1 & - \\
\hline neo-Intermedeol & 1658 & 1658 & - & 2.8 & - \\
\hline Bulnesol & & & & & \\
\hline 3-Ethyl-6-methoxy-2-Naphthol & 1674 & 1676 & - & 4.7 & - \\
\hline Farnesol $^{\mathrm{d}}$ & 1718 & - & 0.1 & - & - \\
\hline Benzyl benzoate & 1760 & 1759 & - & 12.7 & - \\
\hline 1,2-Benzenedicarboxylic acid & 19171 & 1917 & 1.5 & 0.3 & - \\
\hline Hexadecanoic acid & 1959 & 1959 & 0.1 & - & - \\
\hline (Z)-9-Octadecamide & 2398 & 2398 & 0.2 & 5.4 & - \\
\hline (Z)-13-Docosenamide & 2499 & 2499 & 2.7 & - & - \\
\hline \multicolumn{3}{|c|}{ Total } & 96.9 & 96.5 & 94.3 \\
\hline \multicolumn{3}{|c|}{ Monoterpene hydrocarbons } & 88.4 & 14.0 & 34.2 \\
\hline \multicolumn{3}{|c|}{ Oxygenated monoterpenes } & 1.5 & 3.3 & 20.9 \\
\hline \multicolumn{3}{|c|}{ Sesquiterpene hydrocarbons } & 2.0 & 28.1 & 24.7 \\
\hline \multicolumn{3}{|c|}{ Oxygenated sesquiterpenes } & 0.5 & 20.6 & 14.5 \\
\hline \multicolumn{3}{|c|}{ Aromatic compounds } & - & 12.1 & - \\
\hline \multicolumn{3}{|c|}{ Aromatic esters } & - & 12.7 & - \\
\hline \multicolumn{3}{|c|}{ Others } & 4.5 & 5.7 & - \\
\hline
\end{tabular}

${ }^{\mathrm{a} C}$ Compounds identified by RI from column, co-injection, literature MS pattern and literature retention indices, except where stated; ${ }^{b}$ Retention indices on HP-5 MS capillary column; ${ }^{\mathrm{C}}$ Literature retention indices; - not identified and not found in Literature; ${ }^{\mathrm{d}}$ correct isomer not identified; Z.c = Zingiber collinsii; C.k = Croton kongensii; G. $a=$ Goniothalamus albiflorus. 
The classes of compounds present in C. kongensis were monoterpenes (16.2\%), sesquiterpenes (48.7\%), aromatic ester (12.7\%), aromatic compounds (12.1\%) among others. The main compounds of $C$. kongensis were benzyl benzoate (12.7\%), $\beta$-selinene (9.8\%), bulnesol (8.0\%) and $\alpha$-selinene (5.4\%). $\alpha$-Pinene (5.4\%), $\alpha$-ter- pinene (3.5\%) and camphene (2.3\%) were the representatives of the monoterpene compounds. Two unusual constituents of essential oils, namely 5,6,7,8-tetrahydroquinoxaline (7.4\%) and 3-ethyl-6-methoxy-2-naphthol (4.7\%) were also present in significant amounts (Table 1). This report was the first of its kind aimed at characterizing the volatile compound present in C. kongensis. However, the compositions of essential of some Croton species from Vietnam had been reported in literature. The oil of Croton cascarilloides consisted mainly of $\alpha$-pinene (10.5\%), $\beta$-caryophyllene (13.5\%), $\alpha$-humulene (5.9\%), germacrene $\mathrm{D}(6.0 \%)$ and $\alpha$-selinene (6.7\%) while cyclohexanone (6.8\%), cis-carane (6.5\%), 1-menthol (30.4\%) and benzyl benzoate (18.8\%) were the main constituents of Croton chevalieri. Linalool (7.8\%), bicycloelemene (8.0\%), $\beta$-caryophyllene (10.1\%), $\alpha$-humulene (7.1\%), $\beta$-bisabolene (9.6\%) and $\beta$-sesquiphellandrene (6.9\%) could be identified in higher amounts in Croton tonkinensis [15]. Some major compounds of previously studied Croton oils from Vietnam were not detected in the oil of $C$. kongensis. These were cis-carane, 1-menthol, $\beta$-bisabolene, $\beta$-sesquiphellandrene and cyclohexanone.

As could be seen in Table 1, monoterpenes (53.4\%) and sesquiterpenes (39.2\%) were the main class of compounds present in G. albiflous. The major constituents were identified to be $\alpha$-pinene (26.2\%), 1, 8-cineole (9.7\%) and caryophyllene oxide (10.6\%). Quantitative amounts of $\alpha$-calacorene (4.7\%), $\alpha$-ylangene (4.0\%), dehydroaromadendrene (3.3\%) and ledol (3.2\%) were also present in the oil. We reported earlier the composition of the leaf oil from Nghệan Province, to be benzoic acid (18.4\%), $\beta$-caryophyllene (12.4\%) and $\alpha$-pinene (10.3\%) while limonene (21.2\%), $\beta$-caryophyllene (12.8\%) and $\alpha$-phellandrene (9.3\%) were identified in stem [11]. Benzoic acid, a major compound in previous study was not identified in the present sample, which also had low content of $\beta$-caryophyllene (2.7 vs. 12.4\%). Our previous studies on other Goniothalamus revealed that the leaf oil of Goniothalamus macrocalyx was rich in $\alpha$-pinene (50.0\%) $\beta$-caryophyllene (9.9\%), $\alpha$-cadinol (5.3\%) and $\beta$-selinene (5.2\%) while $\alpha$-pinene (33.4\%), viridiflorol (18.5\%) and $\beta$-caryophyllene (12.4\%) were the abundant compounds of Goniothalamus tamirensis [11]. Literature information indicated that $\alpha$-pinene (44.5\%), $\beta$-pinene (22.1\%) and $\beta$-phellandrene (12.0\%) were the quantitative compounds of Goniothalamus glabraciamus [16]. Both qualitative and quantitative variations in chemical compositions could be observed between the various investigated samples.

\section{Acknowledgements}

Authors are grateful to Mrs. Ogunwande Musilimat for the typesetting of the manuscript.

\section{References}

[1] Dai D.N., Thang T.D., Chau L.T.M. and Ogunwande, I.A. (2013) Chemical Constituents of the Root Essential Oils of Zingiber rubens and Zingiber zerumbet. American Journal of Plant Sciences, 4, 7-10.

http://dx.doi.org/10.4236/ajps.2013.41002

[2] Dai D.N., Thang T.D., Thai T.H., Thanh B.V. and Ogunwande, I.A. (2013) Terpene Composition of Three Species of Gymnosperm from Vietnam. American Journal of Plant Sciences, 4, 2031-2038. http://dx.doi.org/10.4236/ajps.2013.410254

[3] Theilade I. andMood, I.J. (1999) A New Species of Zingiber (Zingiberaceae) from Vietnam. Nordic Journal of Botany, 19, 525-527. http://dx.doi.org/10.1111/j.1756-1051.1999.tb01134.x

[4] Prabhakaran, N.K.P. (2013) The Agronomy and Economy of Turmeric and Ginger: The Invaluable Medicinal Spice Crops. Elsevier, Berlin, 510.

[5] Hanelt, P., Kilian R. and Kilian, W. (2001) Croton. In: Hanelt, P. Ed, Mansfeld's Encyclopedia of Agricultural and Horticultural Crops, Springer, Berlin, 1213. http://dx.doi.org/10.1111/j.1756-1051.1999.tb01134.X

[6] Thongtan J., Kittakoop P., Ruangrungsi N., Saenboonrueng J. and Thebtaranonth Y. (2003) New Antimycobacterial and Antimalarial 8,9-Secokaurane Diterpenes from Croton kongensis. Journal of Natural Products, 66, 868-870. http://dx.doi.org/10.1021/np030067a

[7] Chen, W., Yang, X.-D., Zhao, J.-F., Yang, J.-H., Zhang, H.-B., Li, Z.-Y. and Li, L. (2006) Three New, 1-Oxygenated ent-8,9-Secokaurane Diterpenes from Croton kongensis. Helvetica Chimica Acta, 89, pp. 537-541. http://dx.doi.org/10.1002/hlca.200690057

[8] Chen, W., Yang, X.-D., Zhao, J.-F., Zhang, H.-B. and Li, L. (2007) Two New, 1-Oxygenated ent-Kaurane-Type Diter- 
penes from Croton kongensis. Helvetica Chimica Acta, 90, 1554-1558. http://dx.doi.org/10.1002/hlca.200790162

[9] Yang, X.-D., Chen, W., Zhao, J.-F., Yang, L.-J., Zhang, H.-B. and Li, L. (2009) Ent-kaurane Diterpenes and Phenolic Compounds from Croton kongensis (Euphorbiaceae). Biochemical Systematics and Ecology, 37, 237-240. http://dx.doi.org/10.1016/j.bse.2009.03.007

[10] Ban, N.T. (1998) Goniothalamus macrocalyx. In IUCN Red List of Threatened Species. International Union for Conservation of Nature (IUCN) Publication, Gland.

[11] Thang T.D., Huong, L.T., Dai D.N. and Ogunwande, I.A. (2013) Essential Oil Compositions of Goniothalamus macrocalyx Ban., Goniothalamus albiflorus Ban., and Goniothalamus tamirensis Pierre ex Fin. \& Gagnep. from Vietnam. Natural Product Research, 27, 1999-2005. http://dx.doi.org/10.1080/14786419.2013.814051

[12] (1997) Vietnamese Pharmacopoeia, Medical Publishing House, Hanoi.

[13] Adams, R.P. (2007) Identification of Essential Oil Components by Gas Chromatography/Quadrupole Mass Spectrometry. 4th Edition, Allured Publishing, Carol Stream.

[14] Joulain, D. and Koenig, W.A. (1998) The Atlas of Spectral Data of Sesquiterpene Hydrocarbons. E. B. Verlag, Hamburg.

[15] Dai, D.N., Huong, L.T., Thang, T.D. and Ogunwande, I.A. (in Press) Chemical Constituents of Essential Oils of the Leaves of Three Species of Croton (Euphorbiaceae) from Vietnam. Chemistry of Natural Compound.

[16] Dai, D.N., Thang, T.D., Hoi, T.M. and Dung, N.X. (2009) Chemical Composition of the Leaf Essential Oil of Goniothalamus glabracianus (Baill.) Ast from Hatinh. Proceedings of the 3rd National Scientific Conference on Ecology and Biological Resources, Hanoi, 20-26 October 2009, 938-941. 